\title{
Acoustic Monitoring (RFM) of Total Hip Arthroplasty Results of a CADAVER STUdy
}

\author{
A. C. Unger ${ }^{1}$, H. Cabrera-Palacios ${ }^{2}$, A. P. Schulz ${ }^{1,3}$, Ch. Jürgens ${ }^{1,3}$, A. Paech ${ }^{1}$ \\ ${ }^{1}$ University Hospital Schleswig Holstein, Campus Lübeck, Department of Traumatology, Lübeck, Germany , \\ ${ }^{2}$ Regio Klinken Elmshorn, Uetersen, Germany, \\ ${ }^{3}$ BG Trauma Hospital Hamburg, Hamburg, Germany
}

\begin{abstract}
Introduction: At present there are no reliable non-traumatic and non- invasive methods to analyse the healing process and loosening status after total hip replacement. Therefore early as well as late loosening of prosthesis and interface component problems are difficult to be found or diagnosed at any time.

Methods: In a cadaver study the potential application of Resonance Frequency Monitoring (RFM) will be evaluated as a non-invasive and non-traumatic method to monitor loosening and interface problems in hip replacement. In a 65 year old female cadaver different stability scenarios for a total hip replacement (shaft, head/modular head and cup, ESKA, Luebeck, Germany) are simulated in cemented and cement less prosthesis and then analysed with RFM. The types of stability vary from secure/press-fit to interface-shaft disruption.

Results: The RFM shows in cemented as well as cement less prosthesis significant intra-individual differences in the spectral measurements with a high dynamic $(20 \mathrm{~dB}$ difference corresponding to the factor $100(10000 \%))$, regarding the simulated status of stability in the prosthesis system.

Conclusion: The results of the study demonstrate RFM as a highly sensitive non-invasive and non-traumatic method to support the application of RFM as a hip prosthesis monitoring procedure. The data obtained shows the possibility to use RFM for osteointegration surveillance and early detection of interface problems, but will require further evaluation in clinical and experimental studies.
\end{abstract}

Key words: Acoustics, Frequency-Resonance, Biomechanics, Bone Cements, Femur/pathology/ultra structure, Hip Prosthesis

\section{INTRODUCTION}

Worldwide more than 1.2 million patients were treated with Total Hip Arthroplasty (THA) annually [10]. In Germany it is around 180.000 per year [20]. While society is getting older, they get more active, the number of THA will rise in the following years. Aseptic loosening of the prosthesis is a major complication despite improving the operation techniques and the material in the last decades. Because of aseptic loosening, 10\% of all Total Hip Replacements are revised within ten years [25]. At present time, still 10\% of all revision operation after THA are unnecessary, because intraoperative the prosthesis has to be judged as stable [9, 39].

Diagnostic tools for detection of aseptic loosening are despite clinical evaluation the use of images like routine radiography, subtraction arthrography, nuclear arthrography and bone-scintigraphy $[14-17,24,27,29$, $30,38]$. Although these examination tools are extensively described in literature, at present time there is no diagnostic method reliable enough to analyse the cement mantel interface and the bone integrity of a THA months or years after the replacement $[1,2,4-6$, 13, 21, 24, 27, 29, 34, 36].

Plain radiography and bone-scintigraphy are still the standard investigations for prosthesis loosening [35, 37]. Inter-observer variability and technique variations as well as unnecessary $\mathrm{x}$-ray exposure make these methods difficult and undependable to detect accurately early and late loosening of the components [3, $18,26,8]$.

Often micro and macro movements as well as bone resumption have led to a loss of bone substance around the weight bearing area of the prosthesis [11, 19, 28, 33].

In a battery of tests the possible application of Resonance Frequency Monitoring (RFM) as a method of hip prosthesis integrity has been evaluated in a cadaver model with surrounding soft tissues.

This kind of acoustic measuring has been tried and tested to be reliable for material testing and quality control in the fields of aerospace engineering as well as in the car industry for many years. The integrity of the material union (welded, joined, adhered, etc) is tested through acoustic analysis.

\section{Methods}

Based on previous studies using RFM the evaluation of RFM for hip prosthesis monitoring will be carried out in a cadaver model [40].

According to a pre-established protocol RFM will be used in different batteries of tests. The resonance frequencies of a human cadaver femur with all surrounding soft tissue will be analysed (Test A) as well as 
the signal link and signal chain (Test D). Furthermore the resonance frequencies of different types of prosthesis will be analysed in vivo. A cementless stem with increasing stability (Test B), a cement less stem with modular head (Test C) and a cemented femoral stem with a cementless cup (Test E) will be tested. For Test $\mathrm{B}$ and $\mathrm{E}$ the two possible scenarios of secure and loose prosthesis (press-fit vs. loose, intact vs. disrupted cement mantel) are tested.

The tests were performed at a 65-year-old female cadaver not prepared for anatomic dissection in the Institute of Anatomy at the University of Schleswig Holstein, Campus Luebeck. The used implants and instruments as well as the equipment for RFM testing were supplied by ESKA Implants AG Luebeck and UVC Engineering Hamburg.

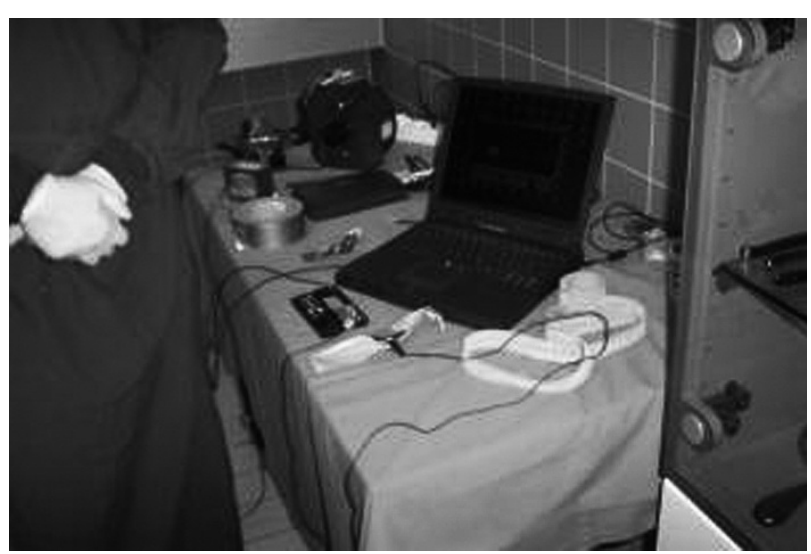

Picture 1: Laptop including sound card and special microphone.

The frequencies measuring were performed with an electronic microphone, which could accurately detect very low frequencies and minor vibrations. The results of the frequency data's were analysed with special acoustic software (Adobe Audition 12.5, Adobe Systems Incorporated, San Jose, California, USA).

In the graphic representation the $\mathrm{x}$-axis shows the time (seconds), the y-axis represents the frequencies from 0 to $22000 \mathrm{~Hz}$. The colours correspond to the sound intensity at a particular point of the time- frequency level. In this respect the graphic is tri-dimensional.
The results of the measurements represent intra-individual differences with high dynamic (e.g. $20 \mathrm{~dB}$ ). These variations correspond to a significant change of the factor $100(10000 \%)$. Such highly dynamic differences can be easily detected. The statistic data of the results were performed by means of the correlation analysis of the frequency spectrum.

\section{Measured Signals - TeChNOLOGY AND SigNIFICANCE}

The recorded signal chain can be studied according to the system theory of telecommunication and communication engineering. A chain of signal transmitters and signal transducers exist. Each one is linked to the chain and can be analysed with a so called transmissions-function. The transmission-function can be described equal as frequency $\mathrm{A}(\mathrm{f})$ as well as time $\mathrm{A}(\mathrm{t})$. Having a closer look at the description of the frequencies, the output signal (measured signal) of the complete signal chain can be formed from the product of the transmission-function of each single link through this formula.

$\mathrm{Y}(\mathrm{f})=\mathrm{A}(\mathrm{f}) * \mathrm{~B}(\mathrm{f}) * \mathrm{C}(\mathrm{f}) \ldots \ldots * \mathrm{X}(\mathrm{f})$

Y (f): $\quad$ Spectral function output signal

A (f), B (f),...: Transmission-function of the chain links $\mathrm{X}(\mathrm{f})$ : $\quad$ Spectral function input signal

The output signal Y (f) corresponds to the electric signal. The input signal X (f) corresponds to the spectral function of the hit.

The transmitting elements in the study are microphone, skin and soft tissue, bone, cement (when applied), gaps between bone and prosthesis or cement and prosthesis and prosthesis.

\section{Objective of Measurement Technology}

Changes in each inner transfer function (for example $\mathrm{C}(\mathrm{f})$ ) have a direct proportional effect on the output signal Y (f) when the transfer links are constant (for example $\mathrm{X}(\mathrm{f})$, A (f), B (f)....). Therefore general changes in $\mathrm{Y}(\mathrm{f})$ are sufficient for a comparative assessment of $C(f)$.

If $\mathrm{C}(\mathrm{f})$ shows a distinguishable structure (for example clear resonance peaks) compared to the other signals $X(f), A(f), B(f)$ and these functions (X (f), A (f),

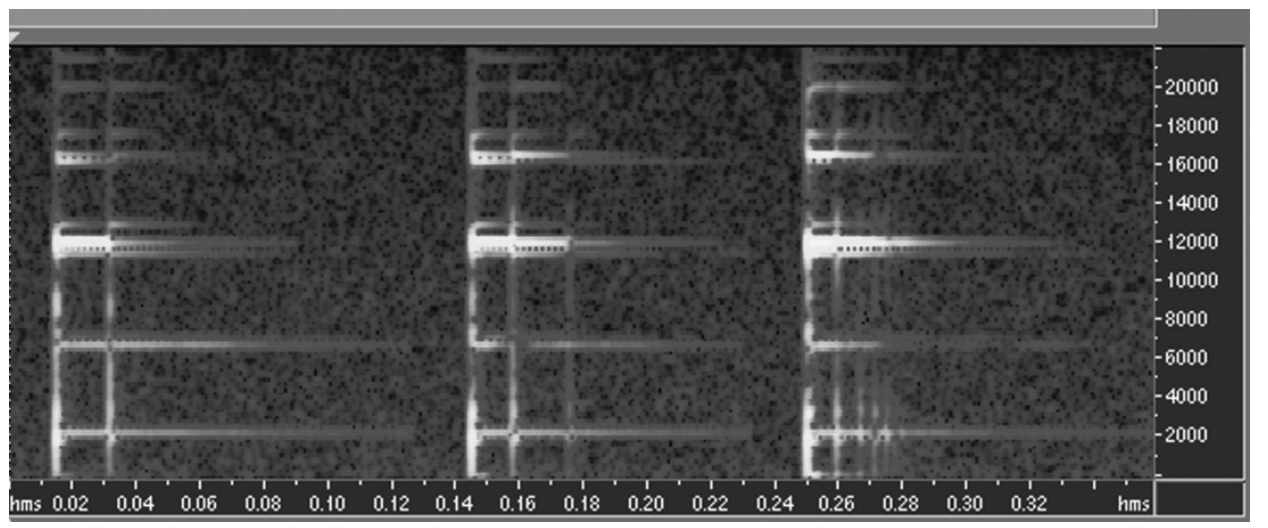

Picture 2: Example of a tridimensional frequency spectrum with time and frequency axis as well as sound intensity. 
B (f)) show a generally flat and structure-less pattern, then the signal of $\mathrm{Y}(\mathrm{f})$ alone allows a conclusion regarding $C(f)$ without any reference signal. In this case $\mathrm{Y}(\mathrm{f})$ would be an absolute criterion. All other transfer functions as well as the signal of the output function $\mathrm{X}(\mathrm{f})$ should be flat.

\section{INFORMATION ON THE DECIBEL SCALE}

The decibel-scale $(\mathrm{dB})$ is widely used and well known for signal measurement. The dB-scale is also used for creating spectral images. In general one decibel corresponds to a 10 fold logarithmic of the relation between two signal energies.

\begin{tabular}{|c|c|c|c|}
\hline$+3 \mathrm{~dB}$ & \multicolumn{3}{|l|}{ a double } \\
\hline$+6 \mathrm{~dB}$ & a quadrupl & & \\
\hline$+10 \mathrm{~dB}$ & a tenfold ( & & \\
\hline$+13 \mathrm{~dB}$ & $\mathrm{x} 20$ & & \\
\hline$+16 \mathrm{~dB}$ & $\mathrm{x} 40$ & & \\
\hline$+20 \mathrm{~dB}$ & x 100 & $-20 \mathrm{~dB}$ & a hundredth $1 / 100$ \\
\hline $30 \mathrm{~dB}$ & x 1.000 & $-30 \mathrm{~dB}$ & a thousandth $1 / 1.000$ \\
\hline $40 \mathrm{~dB}$ & x 10.000 & $-40 \mathrm{~dB}$ & $1 / 10.000$ \\
\hline $50 \mathrm{~dB}$ & x 100.000 & $-50 \mathrm{~dB}$ & $1 / 100.000$ \\
\hline
\end{tabular}

The dynamic scale of the used measurements is approximately $48 \mathrm{~dB}$, corresponding to a signal relation of 1: 60.000 .

\section{RESULTS}

Test A - Direct Measurement after Opening

The Watson-Jones surgical approach was chosen for access to the hip joint. After preparation and excision of the ventral part of the joint capsule, the cortex of the femur neck was exposed. The exposed cortex was then hit with a metal device. The monitoring of the measured impulse was performed with a microphone fixed at the lateral femoral condoyle as shown in picture 3 .

Picture 4 shows the measured impulses with its corresponding digital amplitude. Picture number 5 shows a spectral image with a clear maximum of $500 \mathrm{~Hz}$.

The spectral analysis shows that a maximum of frequency appeared very clearly when the impulse is produced over the femur neck. Picture 6 demonstrates the peak at around $500 \mathrm{~Hz}$ with a dynamic of $12 \mathrm{~dB}$ (17 fold signal change) at each given impulse. Consequently a vibrating system is available at $500 \mathrm{~Hz}$ in an anatomi-
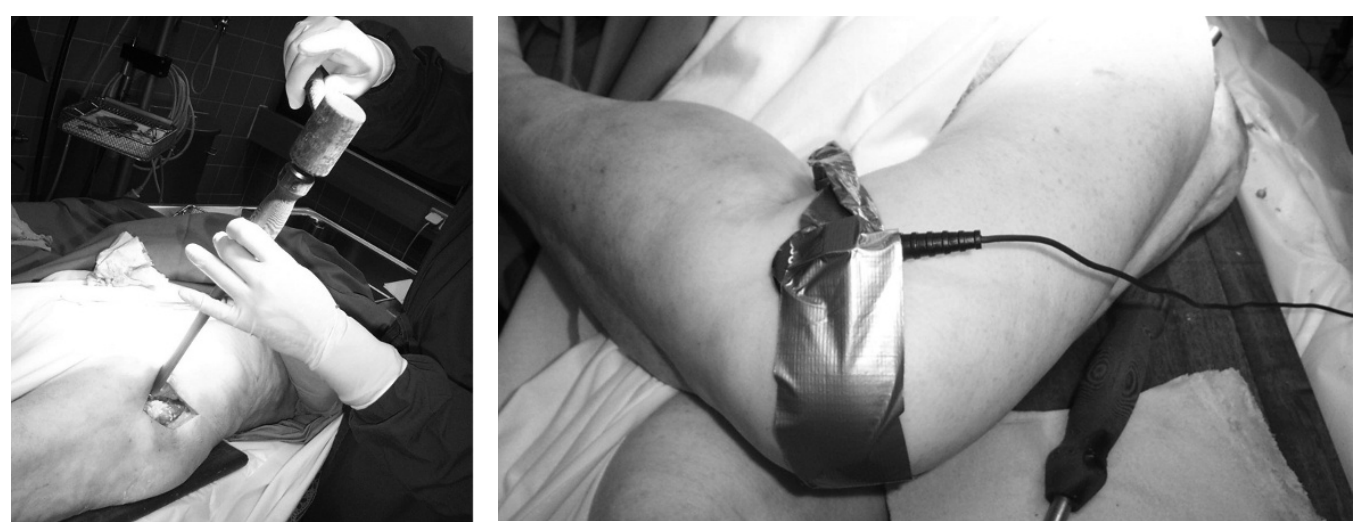

Picture 3: Performing an impulse after direct approach to the femur neck.

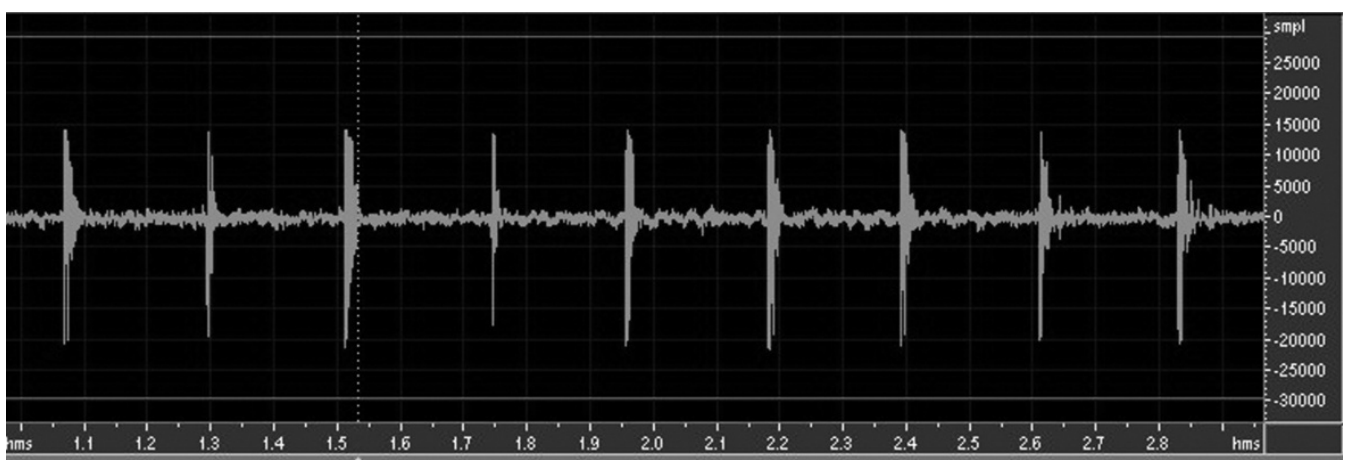

Picture 4: Direct hand hit over the femur neck, signal obtained at the lateral condoyle.

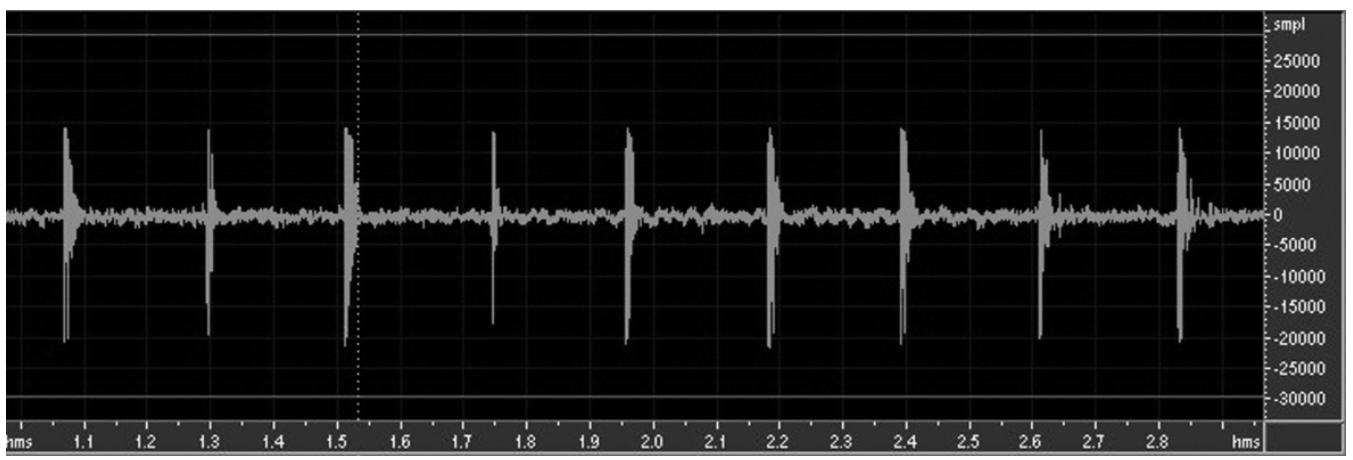

Picture 5: Spectral picture of test A showing a peak at $500 \mathrm{~Hz}$. 


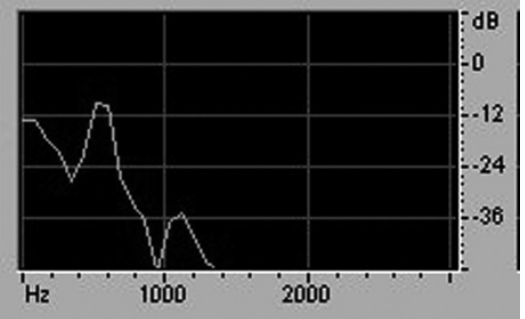

Picture 6: Signal spectrum Y (f) at the position $500 \mathrm{~Hz}$. The peak is clearly shown at $12 \mathrm{~dB}$.

cal environment, after an impulse of the femur neck is caused. The analysis of the data also shows that frequencies over $5 \mathrm{kHz}$ are not relevant to the study.

\section{Test B - Prosthesis: Stem Implanted, Cement LEss, Not REDuCED}

In the following battery of tests a size three hip stem from ESKA (Luebeck, Germany) was implanted fol-

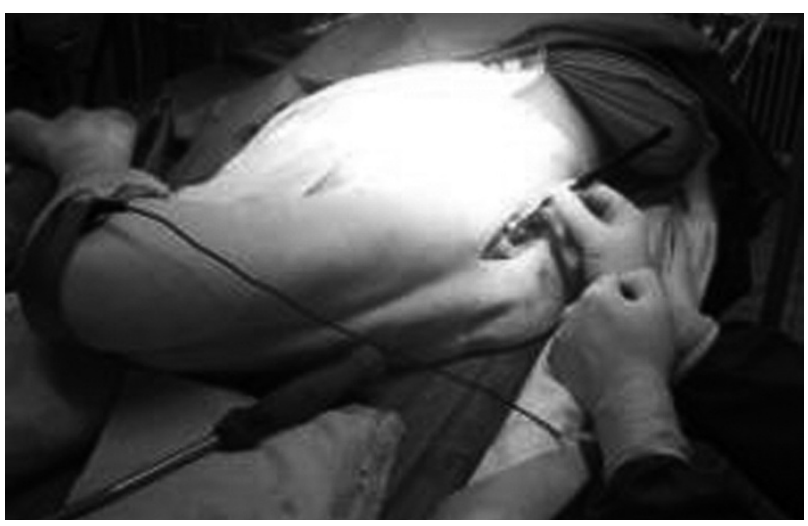

Picture 7: Impulse performed with "ticks" at the femur measured at the lateral condyle. lowing the typical steps to prepare the femoral canal. The size of reamers was increased until the femur accepted the prosthesis with size three. During implantation of the stem, stability increased until the stem reaches the point of press-fit. Picture 7 shows the measurement chain, which was used for frequency analysis at different stages of stability.

Pictures 8 to10 show, that the spectral structures of higher frequencies (metal frequencies) are increasingly dampened. The more stable the prosthesis is the more
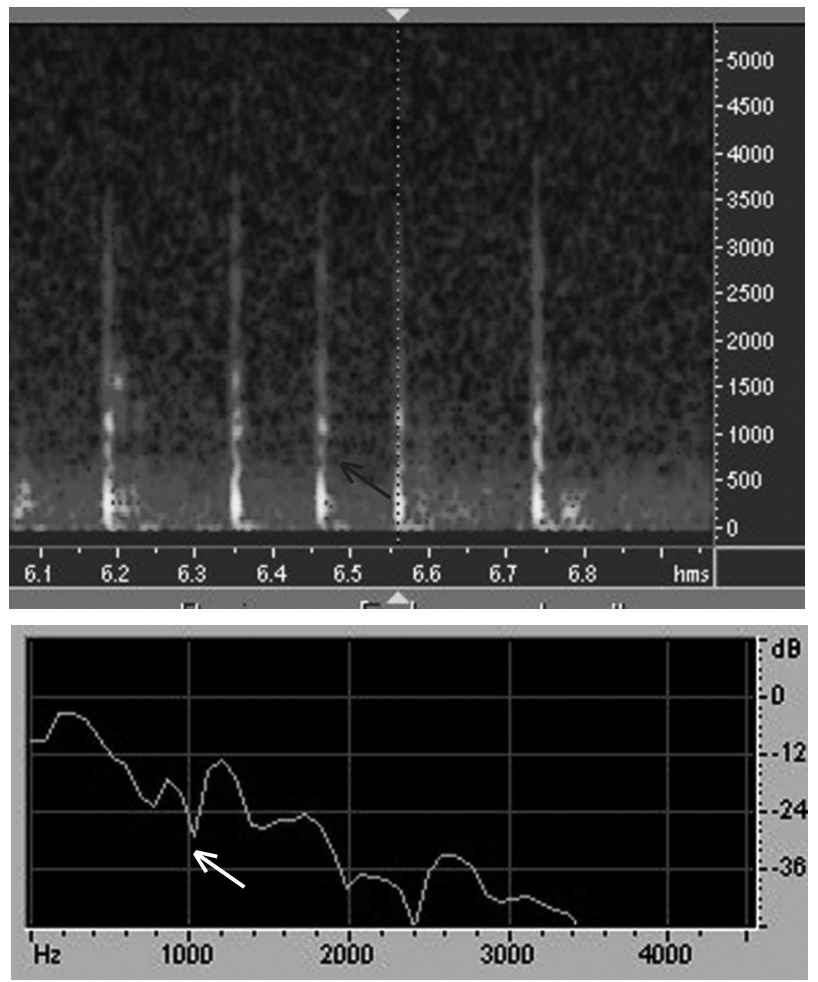

Picture 8: Prosthesis loosely implanted.
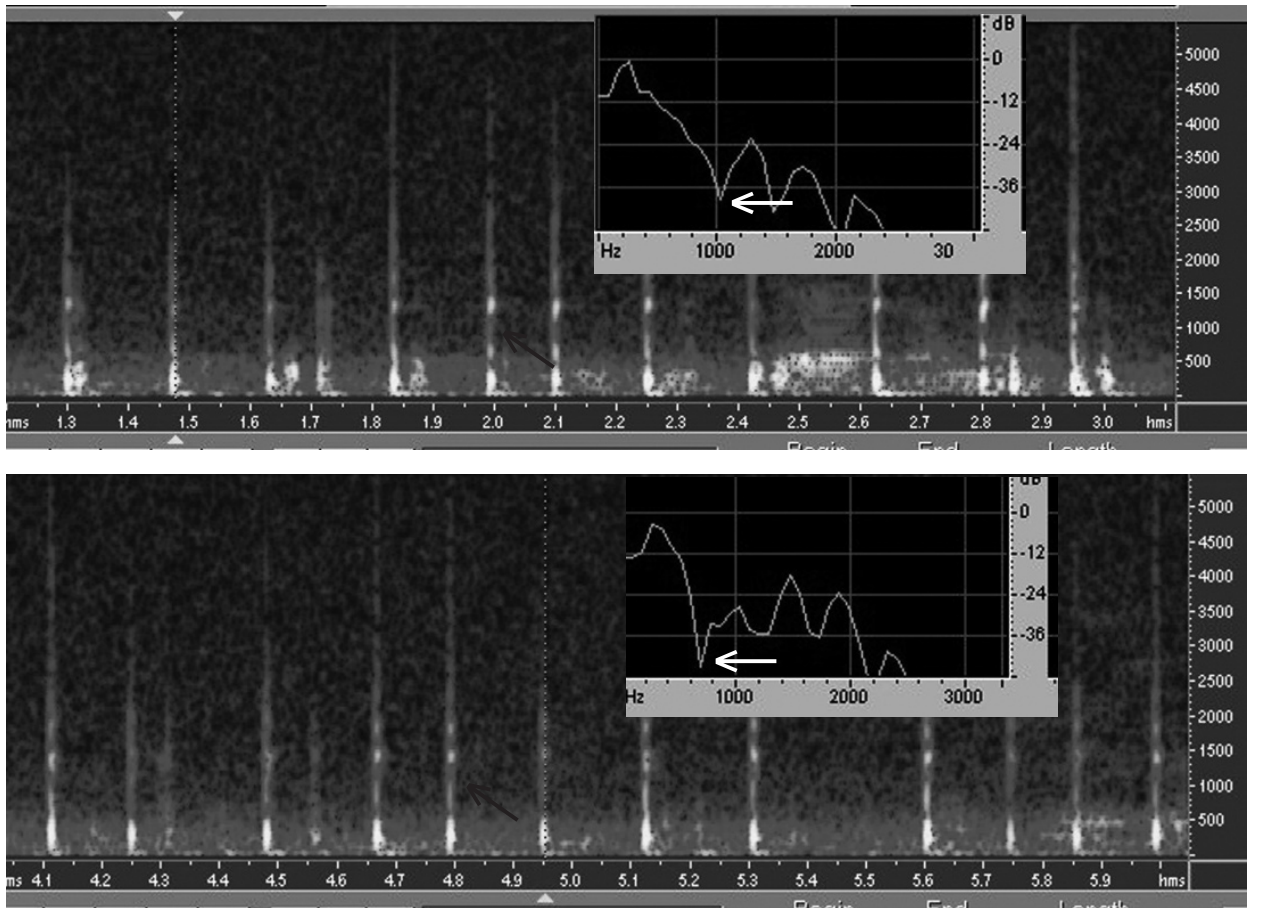

Picture 9: Prosthesis implanted in standard fashion

Picture 10: Prosthesis securely implanted (press-fit) 


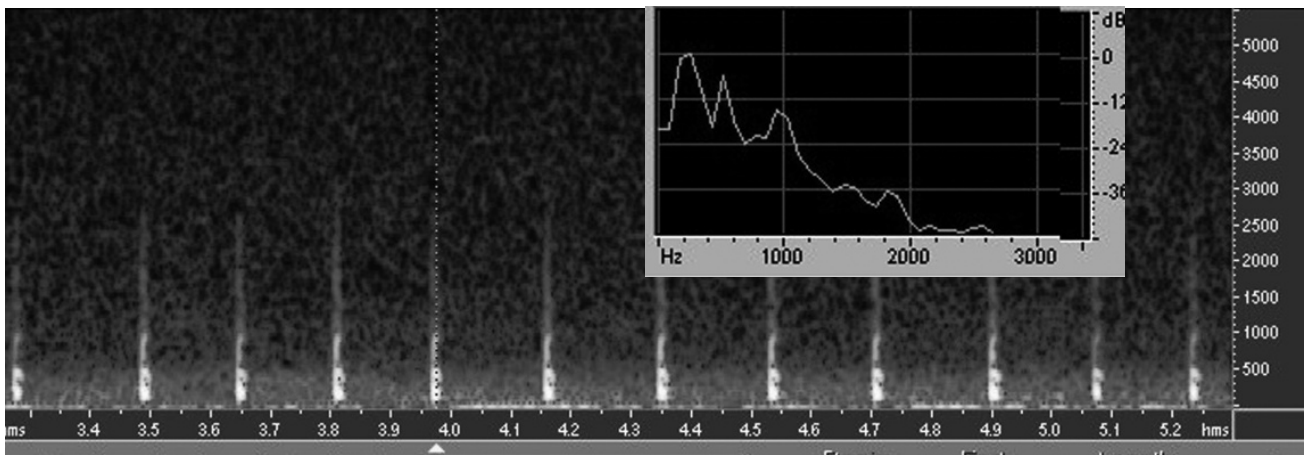

Picture 11: Spectral analysis of press-fit implanted double head prosthesis

dampened the signal becomes. Furthermore spectral structures of lower frequencies (bone frequencies) become clearer and steeper. The frequencies of the prosthesis itself (finger print) are not seen. With increasing stability a clear dynamic change of frequencies from 400 to $800 \mathrm{~Hz}$ is visible in the secure implanted (press-fit) prosthesis. This represents a change in the measurement of more than $36 \mathrm{~dB}$ (= $1 / 5.000)$.

\section{Test C - Prosthesis: Stem Implanted, Cement Less, Modular Head, Reduced}

In this battery of tests we used a cement less implanted stem with a modular double head. The modular double head is applied directly over the conus of the stem and afterwards reduced in the acetabulum.

The measurements show a significant change spring-mass relationship because of application of the heavy metal double head (Picture 11). The spectral analysis detected different frequency structures with low resonance, which can be easily reproduced. It is possible to observe spectral structure changes significantly in quantity and quality.

\section{Test D - Evaluation of a Signal Chain From}

Lateral Femoral CONDOYle to ANTERior Superior Iliac Spine, with Reduced Double Head PROSTHESIS

The battery of tests shows, that a measurement with an induction of impulse through the lateral femoral condoyle and recorded signal taken at the ipsilateal anterior-superior iliac spine is possible without problems as well as the analysis of the signals obtained (Picture 12). The measurements were performed with the prosthesis reduced.

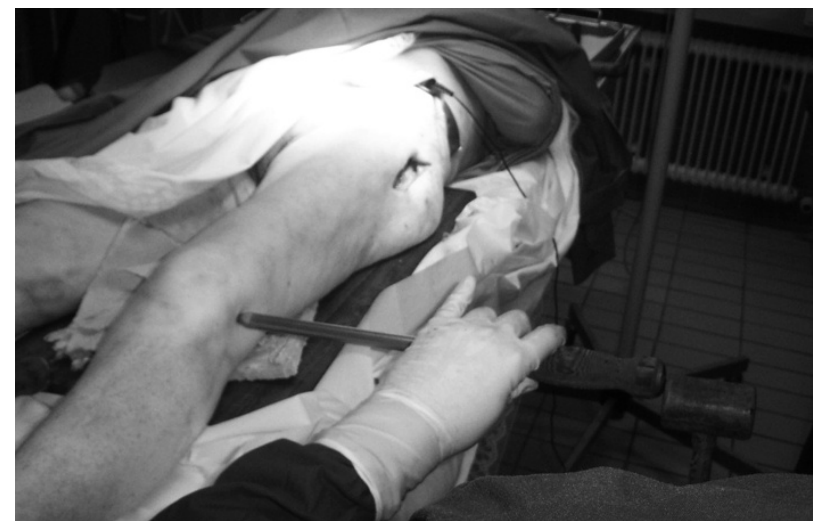

Picture 12: Generation of impulses at the condoyle by hammer strikes.

A spectral correlation analysis of these measurements with 8 impulses shows a very good reproducibility with a correlation of $>0.95$. Frequencies of the tool strike as well as of bone structures below 500 $\mathrm{Hz}$ are visible. A suppression of tool frequencies (Picture 13, frequencies $>1000 \mathrm{~Hz}$ ) is possible, when smaller impulses by the hammer strikes are given.

\section{Test E - Tests on a Hip Replacement with a Cement Less Cup and Cemented Stem}

The tests were performed in three different cases: secure intact-cemented prosthesis, cement mantel disrupted and loose prosthesis.

In this battery of tests a hybrid hip replacement with a cemented stem and cement less cup was tested after application. The hybrid cement technique during hip replacement results in the best interface contact between the femur and hip stem. All measurements

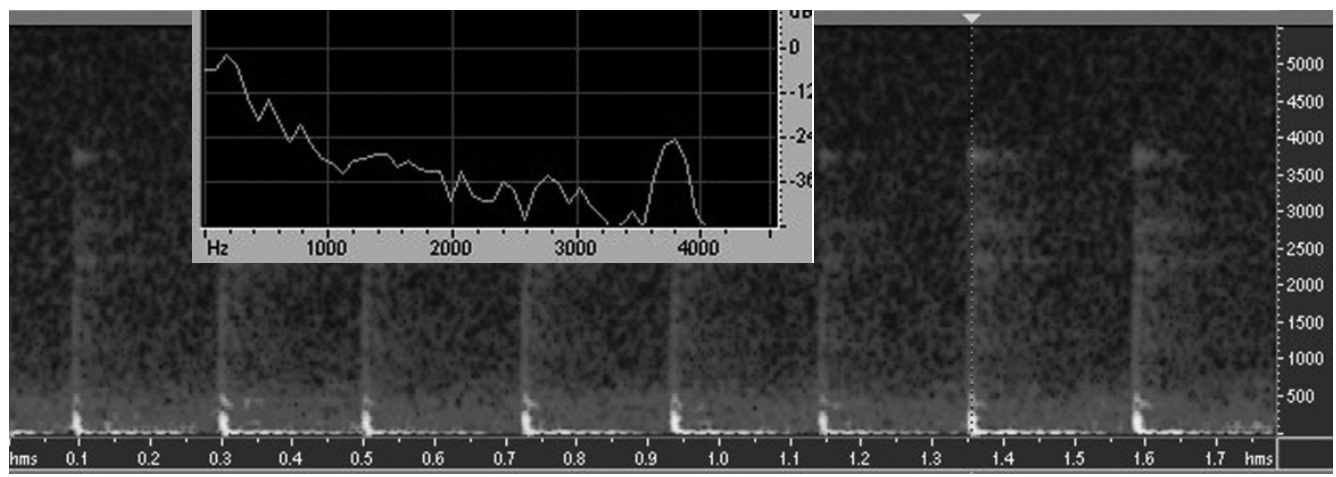

Picture 13: Measurements with a hard impulse in a press-fit implanted double head prosthesis. 


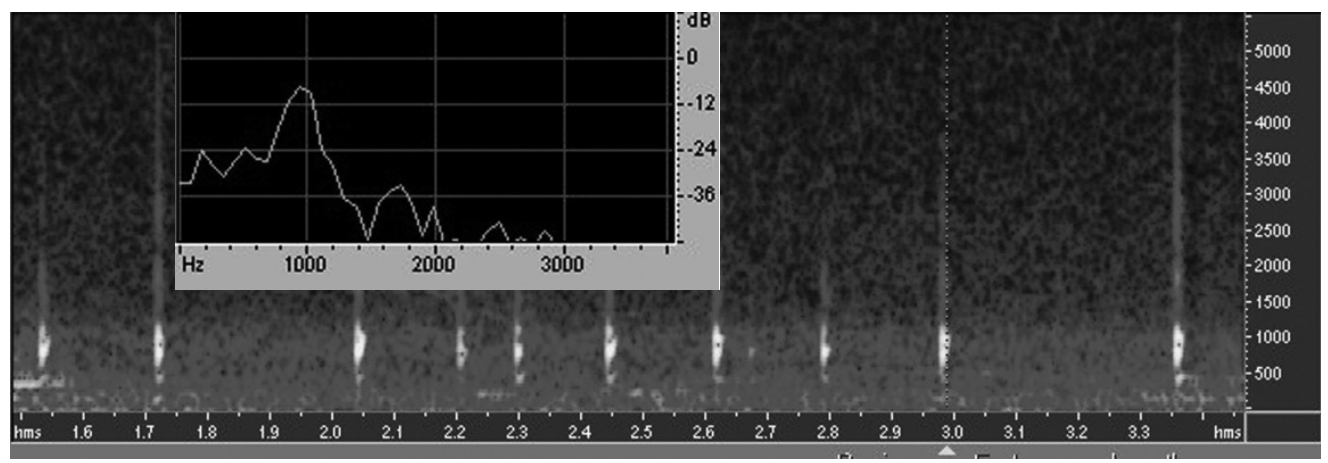

Picture 14: Firm.

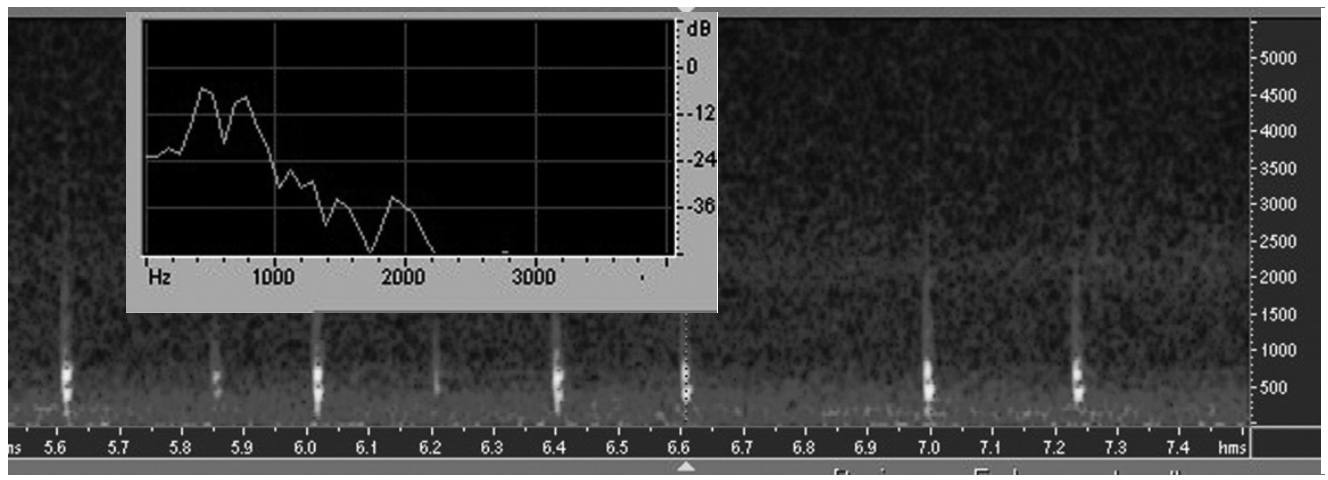

Picture15: Fissured.

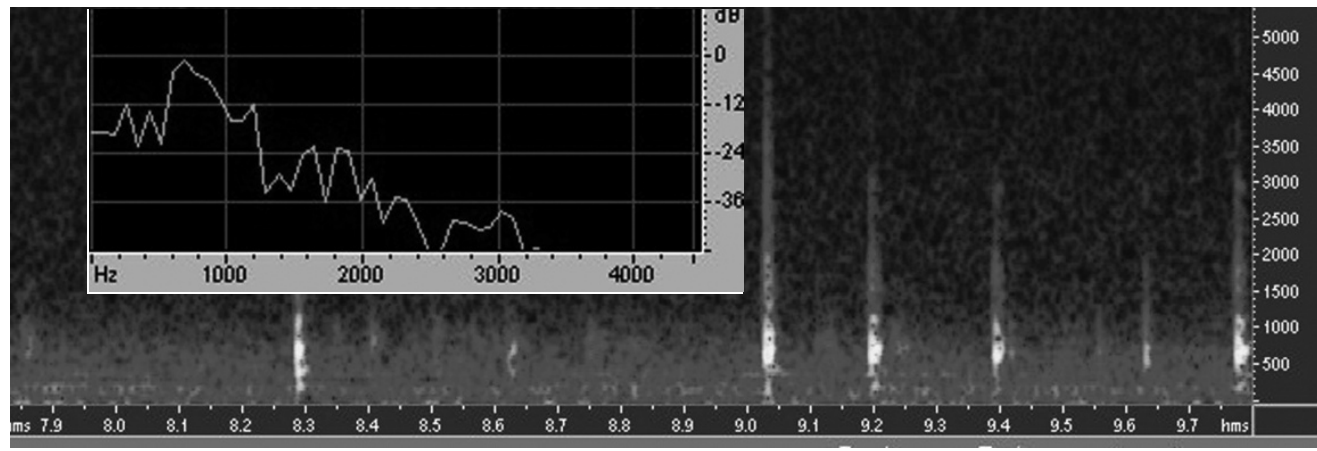

Picture 16: Loose.

were performed in a well reduced prosthesis. Picture 14 shows frequency spectrum of RFM measurement with an optimal firmness. Afterwards the cement mantel was damaged mechanically in order to have macroscopic fissures in the cement within the femur but still maintain clinical firm (Picture 15). Picture 16 demonstrates frequency spectrum of RFM measurement in a clinical and radiographic visible loose prosthesis.

With increasing interface problems (loosening the cement integrity) the absolute resonances are reduced. The resonances become more apparent as an expression of increasingly reduced restoring force in a spring-mass system of total hip replacement. (Picture 14, Firm: $1000 \mathrm{~Hz}$; picture 15 Fissured / 16 Loose $<1000 \mathrm{HZ}$ ).

The increasing mechanical instability leads to an augmented loss of structure of the frequency spectrums and a relatively increased appearance of high frequencies with reduced effectiveness of bone dampening $(>2000 \mathrm{~Hz})$. The changes between the different types of prosthesis stability (firm-fissured-loose) are easy to detect with high dynamic.

\section{CONCLUSION}

The experiments indicate that for surveillance and identification of interface loosening, the observation of changes in bone frequencies is suitable.

Clear signs for correlation between prosthesis stability and bone spectrum were found in this cadaver study.

Metal vibration could not be found in the tests, the bone absorbs the acoustic energy of the metal directly. The vibration mechanics of the system (bone and prosthesis with or without cement) can be explained and described on the basis of the spring-mass effect. For practical application frequencies from $300 \mathrm{~Hz}$ to $3000 \mathrm{~Hz}$ are relevant.

Loose prosthesis corresponds to low restoring forces with a low frequent maximum resonance.

The tests demonstrate in a systematic and impressive way the following characteristics:

Basic spectral patterns around $0,2-2 \mathrm{kHz}$ in firm implanted prosthesis become clearer and steeper while higher frequencies become more dampened. 
The signal and variation dynamics are intensive enough for technical purposes of automatic analysis.

The RFM shows significant intra-individual spectral changes with high dynamics related to the different simulated conditions of stability states in hip prosthesis (cement or cement less). The differences detect represent a dynamic of $20 \mathrm{~dB}$, which is equivalent to factor $100(\sim 10000 \%)$.

To achieve a perfect reproducibility of the test it is important to make sure, that all the geometries of the acoustic environment are kept constant.

\section{DISCUSSION}

The two major complications of hip joint replacement are loosening and infection. A reliable differentiation between these pathological processes can be challenging because both are accompanied by similar clinical symptoms.

At present time still no standardized testing method is established in clinical use to detect loosening of implanted hip arthroplasties. Several study groups have done tests with ultrasound and vibration methods in in vitro settings $[7,12,22,23,31,32]$. Li et al. could nor clearly differentiate between firm and loose prosthesis with vibration analysis [22].

In earlier in vitro investigations our group was able to show typical acoustic characteristics for different hip prosthesis models and the interferences [40].

Based on the studies we evaluated the results in a cadaver model, aged 65 years. The cadaver studies have shown that RFM has the potential to become a non-invasive and non-traumatic tool, which can be used for hip prosthesis integrity monitoring (Test $\mathrm{B}, \mathrm{E})$. Frequencies up to $20 \mathrm{kHz}$ are sufficient for acoustic studies involving different stability scenarios for total hip arthroplasty. The obtained data supports the possible use of RFM for osteo-integrity surveillance or the diagnosis of early interface problems. The correlation analysis of spectral frequencies of all tests gives a very good reproducibility of spectral information within each test. With an average of six hits per test the correlation in all the series is $>0.95$.

\section{REFERENCES}

1. Barentsz, J. O.; Lemmens, J. M.; and Slooff, T. J.: The use of subtraction arthrography in total hip arthroplasties. Rofo, 144(4): 440-6, 1986.

2. Barrack, R. L.; Tanzer, M.; Kattapuram, S. V.; and Harris, W. H.: The value of contrast arthrography in assessing loosening of symptomatic uncemented total hip components. Skeletal Radiol, 23(1): 37-41, 1994.

3. Brand, R. A.; Yoder, S. A.; and Pedersen, D. R.: Interobserver variability in interpreting radiographic lucencies about total hip reconstructions. Clin Orthop Relat Res, (192): 237-9, 1985.

4. Cain, T. M.; Fon, G. T.; Brumby, S.; and Howie, D. W.: Plain film and arthrographic findings in painful total hip arthroplasties with surgical correlation. Australas Radiol, 34(3): 211-8, 1990.

5. Carlsson, A. S., and Gentz, C. F.: Radiographic versus clinical loosening of the acetabular component in noninfected total hip arthroplasty. Clin Orthop Relat Res, (185): 145-50, 1984.
6. Cheung, A.; Lachiewicz, P. F.; and Renner, J. B.: The role of aspiration and contrast-enhanced arthrography in evaluating the uncemented hip arthroplasty. AJR Am J Roentgenol, 168(5): 1305-9, 1997.

7. Davies, J. P.; Tse, M. K.; and Harris, W. H.: Monitoring the integrity of the cement-metal interface of total joint components in vitro using acoustic emission and ultrasound. J Arthroplasty, 11(5): 594-601, 1996.

8. Davis, A. M. et al.: Classifying failed hip arthroplasty: generalizability of reliability and validity. Clin Orthop Relat Res, (415): 171-9, 2003.

9. Dihlmann, W.; Dihlmann, S. W.; and Hering, L.: [Alloarthroplasty of the hip joint. Radiologic diagnosis of loosening and infection in cemented total endoprostheses]. Radiologe, 31(10): 496-505, 1991.

10. Dreinhofer, K. E.; Dieppe, P.; Sturmer, T.; GroberGratz, D.; Floren, M.; Gunther, K. P.; Puhl, W.; and Brenner, H.: Indications for total hip replacement: comparison of assessments of orthopaedic surgeons and referring physicians. Ann Rheum Dis, 65(10): 1346-50, 2006.

11. Freeman, M. A., and Plante-Bordeneuve, P.: Early migration and late aseptic failure of proximal femoral prostheses. J Bone Joint Surg Br, 76(3): 432-8, 1994.

12. Georgiou, A. P., and Cunningham, J. L.: Accurate diagnosis of hip prosthesis loosening using a vibrational technique. Clin Biomech (Bristol, Avon), 16(4): 315-23, 2001.

13. Ginai, A. Z.; van Biezen, F. C.; Kint, P. A.; Oei, H. Y.; and Hop, W. C.: Digital subtraction arthrography in preoperative evaluation of painful total hip arthroplasty. Skeletal Radiol, 25(4): 357-63, 1996.

14. Harris, W. H., and Barrack, R. L.: Contemporary algorithms for evaluation of the painful total hip replacement. Orthop Rev, 22(5): 531-9, 1993.

15. Harris, W. H., and Barrack, R. L.: Developments in diagnosis of the painful total hip replacement. Orthop Rev, 22(4): 439-47, 1993.

16. Hendrix, R. W.; Wixson, R. L.; Rana, N. A.; and Rogers, L. F.: Arthrography after total hip arthroplasty: a modified technique used in the diagnosis of pain. Radiology, 148(3): 647-52, 1983.

17. Koster, G.; Munz, D. L.; and Kohler, H. P.: Clinical value of combined contrast and radionuclide arthrography in suspected loosening of hip prostheses. Arch Orthop Trauma Surg, 112(5): 247-54, 1993.

18. Kramhoft, M.; Gehrchen, P. M.; Bodtker, S.; Wagner, A.; and Jensen, F.: Inter- and intraobserver study of radiographic assessment of cemented total hip arthroplasties. J Arthroplasty, 11(3): 272-6, 1996.

19. Krismer, M.; Stockl, B.; Fischer, M.; Bauer, R.; Mayrhofer, P.; and Ogon, M.: Early migration predicts late aseptic failure of hip sockets. J Bone Joint Surg Br, 78(3): 422-6, 1996.

20. Kruckhans, A. R., and Dustmann, H. O.: Indications, methods, and results of cemented, hybrid, and cementfree implantation of THR. Surg Technol Int, 12: 253-7, 2004.

21. Li, D. J.; Miles, K. A.; and Wraight, E. P.: Bone scintigraphy of hip prostheses. Can analysis of patterns of abnormality improve accuracy? Clin Nucl Med, 19(2): 112-5, 1994.

22. Li, P. L.; Jones, N. B.; and Gregg, P. J.: Loosening of total hip arthroplasty. Diagnosis by vibration analysis. J Bone Joint Surg Br, 77(4): 640-4, 1995.

23. Li, P. L.; Jones, N. B.; and Gregg, P. J.: Vibration analysis in the detection of total hip prosthetic loosening. Med Eng Phys, 18(7): 596-600, 1996.

24. Lieberman, J. R.; Huo, M. H.; Schneider, R.; Salvati, E. A.; and Rodi, S.: Evaluation of painful hip arthroplasties. Are technetium bone scans necessary? J Bone Joint Surg Br, 75(3): 475-8, 1993. 
25. Malchau, H.; Herberts, P.; Eisler, T.; Garellick, G.; and Soderman, P.: The Swedish Total Hip Replacement Register. J Bone Joint Surg Am, 84-A Suppl 2: 2-20, 2002.

26. McCaskie, A. W.; Brown, A. R.; Thompson, J. R.; and Gregg, P. J.: Radiological evaluation of the interfaces after cemented total hip replacement. Interobserver and intraobserver agreement. J Bone Joint Surg Br, 78(2): 191-4, 1996.

27. Miniaci, A.; Bailey, W. H.; Bourne, R. B.; McLaren, A. C.; and Rorabeck, C. H.: Analysis of radionuclide arthrograms, radiographic arthrograms, and sequential plain radiographs in the assessment of painful hip arthroplasty. J Arthroplasty, 5(2): 143-9, 1990.

28. Mjoberg, B.: Fixation and loosening of hip prostheses. A review. Acta Orthop Scand, 62(5): 500-8, 1991.

29. Oyen, W. J.; Lemmens, J. A.; Claessens, R. A.; van Horn, J. R.; Slooff, T. J.; and Corstens, F. H.: Nuclear arthrography: combined scintigraphic and radiographic procedure for diagnosis of total hip prosthesis loosening. J Nucl Med, 37(1): 62-70, 1996

30. Pfahler, M.; Schidlo, C.; and Refior, H. J.: Evaluation of imaging in loosening of hip arthroplasty in 326 consecutive cases. Arch Orthop Trauma Surg, 117(4-5): 205-7, 1998.

31. Qi, G.; Mouchon, W. P.; and Tan, T. E.: How much can a vibrational diagnostic tool reveal in total hip arthroplasty loosening? Clin Biomech (Bristol, Avon), 18(5): 444-58, 2003.

32. Rosenstein, A. D.; McCoy, G. F.; Bulstrode, C. J.; McLardy-Smith, P. D.; Cunningham, J. L.; and TurnerSmith, A. R.: The differentiation of loose and secure femoral implants in total hip replacement using a vibrational technique: an anatomical and pilot clinical study. Proc Inst Mech Eng [H], 203(2): 77-81, 1989.

33. Stocks, G. W.; Freeman, M. A.; and Evans, S. J.: Acetabular cup migration. Prediction of aseptic loosening. J Bone Joint Surg Br, 77(6): 853-61, 1995.

34. Temmerman, O. P.; Heyligers, I. C.; Teule, G. J.; Hoekstra, O. S.; and Raijmakers, P. G.: The value of contrast and subtraction arthrography in the assessment of aseptic loosening of total hip prostheses: a meta-analysis. Eur J Radiol, 56(1): 113-9, 2005.

35. Temmerman, O. P.; Raijmakers, P. G.; Berkhof, J.; David, E. F.; Pijpers, R.; Molenaar, M. A.; Hoekstra, O. S.; Teule, G. J.; and Heyligers, I. C.: Diagnostic accuracy and interobserver variability of plain radiography, subtraction arthrography, nuclear arthrography, and bone scintigraphy in the assessment of aseptic femoral component loosening. Arch Orthop Trauma Surg, 126(5): 316-23, 2006.
36. Temmerman, O. P.; Raijmakers, P. G.; Berkhof, J.; Hoekstra, O. S.; Teule, G. J.; and Heyligers, I. C.: Accuracy of diagnostic imaging techniques in the diagnosis of aseptic loosening of the femoral component of a hip prosthesis: a meta-analysis. J Bone Joint Surg Br, 87(6): 781-5, 2005.

37. Temmerman, O. P. et al.: A comparison of radiographic and scintigraphic techniques to assess aseptic loosening of the acetabular component in a total hip replacement. J Bone Joint Surg Am, 86-A(11): 2456-63, 2004.

38. Weiss, P. E.; Mall, J. C.; Hoffer, P. B.; Murray, W. R.; Rodrigo, J. J.; and Genant, H. K.: 99mTc-methylene diphosphonate bone imaging in the evaluation of total hip prostheses. Radiology, 133(3 Pt 1): 727-9, 1979.

39. Clasbrummel B.; Jettkant B.; DeLuca N.; Muhr G.; Möllenhoff G.: Endoprothesenlockerungen. Trauma Berufskrankh, 9: 84-87, 2007

40. Paech A.; Schulz A.P.; Nassutt R.; Kiene J.; Wenzl M.E.; Jürgens C.H.: Acoustic Properties of Femoral Components of Hip Endoprostheses Analysing Using Frequency-Resonance-Measurement in a Soft Tissue Simulation Model. Research Journal of Medical Science, 1(2):118123, 2007.

Received: March 29, 2009 / Accepted: April 14, 2009

Address for correspondence:

Andreas Paech

University Hospital Schleswig Holstein

Campus Lübeck

Department of Traumatology

Ratzeburger Allee 160

23538 Lübeck

Germany

Tel.: +49-451-5000

E-mail: Andreas.Paech@uk-sh.de 